\title{
A proposta criativa de Étienne Decroux e a passagem de fronteiras: a interculturalidade como procedimento artístico
}

Bya BRAGA ${ }^{1}$

1.

Bya Braga (nome artístico de Maria Beatriz Mendonça) é atriz e diretora cênica. Professora e pesquisadora na Universidade Federal de Minas Gerais, Escola de Belas Artes, Curso de Teatro e Programa de Pós-Graduação em Artes. Seu campo de trabalho inclui Processos criativos, Teatro físico, Mímica Corporal Dramática e Atuação, entre questões sobre a performatividade e corporeidade. Coordena o Grupo de Pesquisa LAPA - Laboratório de Pesquisa em Atuação/ CNPq. É atual Diretora da Escola de Belas Artes da UFMG.

\begin{abstract}
This work reflects on the creative proposal of Étienne Decroux, through art Corporeal Mime, in its relation to intercultural thinking. This analysis finds initial support at the concept of theater as a phenomenon of confluence. It seeks to recognize interculturalism as a border crossing, departing from the exercise of actor / performer on himself and his cultural identity, opening himself to a dialogical scenic behavior which might create gestualities and express performative hybrids.
\end{abstract}

Keywords: Corporeal Mime. Interculturalism.

Performative hybrids. 
Os monstros, felizmente, existem não para nos mostrar o que não somos, mas o que poderíamos ser. (...) Que corpo podemos nós ter hoje?

José Gil

Roteiros. Roteiros. Roteiros. Roteiros. Roteiros. Roteiros.

Roteiros.

Oswald de Andrade

\section{(...) blasfemar é sonhar. Homi K. Bhabha}

O interculturalismo nas artes da cena pode ser investigado a partir de algumas práticas e teorias tais como a noção de duplo em Antonin Artaud, as experiências de Jerzy Grotowski na arte como veículo, as vivências sobre culturas e cena de Peter Brook, e também de Ariane Mnouchline, bem como por meio das proposições de Eugenio Barba e Nicola Savarese sobre as manifestações espetaculares entre Ocidente e Oriente. No Brasil também possuímos referências específicas, como a carnavalização e antropofagização na cena de José Celso Martinez Correa, as pesquisas práticas de atores do Grupo Lume, os estudos da performance realizados por Renato Cohen², entre outros. A temática da interculturalidade não é, portanto, uma discussão nova no campo da criação performativa, mas reconhecemos sua ênfase nas últimas décadas articulada com reflexões oriundas dos Estudos Culturais e Pós-Coloniais.

Neste texto, experimentamos um modo específico de pensar e praticar a interculturalidade nas artes da cena com o foco sobre o fazer do atuador (ator/performer), em um topos de atuação expandida e paradoxal. Para esta reflexão, destacamos a arte Mímica Corporal Dramática como referência principal, técnica cênica francesa criada por Étienne M. Decroux (18981991). ${ }^{3}$ Junto dela, abordamos questões sobre alteridade e hibridismo, o que nos dá suporte para a compreensão sobre o aparecimento de símbolos "misturados" na atuação. Aqui chamaremos isso de composição de "híbridos performativos". O performativo é uma produção expressiva que pode conter, em si, processos de adaptação, contaminação, fusão, ou mesmo transcriação de aspectos artísticos e culturais. Assim, falar em "híbrido performativo" pode soar redundante. No entanto, a ênfase aqui é proposital porque queremos sinalizar a vivência do híbrido na atuação como um dos resultados do processo intercultural. Este "efeito" se fundamenta em princípios tais como o entendimento de que a noção de identidade humana não é algo estável e fixado. Ao contrário. E, no Brasil, país com
2.

Conferir o artigo de Renato Cohen: Cartografia da cena contemporânea: matrizes teóricas e interculturalidade. São Paulo: Revista Sala Preta/ PPGAC/USP, 2001, p. 105-112; o livro de Renato Ferracini, Café com queijo. Corpos em criação. Campinas: HUCITEC, 2012; e o livro de Suzi Frankl Sperber, Contadores de histórias da Amazônia ribeirinha. Campinas: HUCITEC, 2012. 3. Sobre a arte Mímica Corporal Dramática e suas relações com a arte da cena contemporânea, conferir o livro: Étienne Decroux e a artesania de ator. Caminhadas para a soberania. Belo Horizonte: Ed. UFMG, 2013, de nossa autoria. 
bases culturais sincréticas, mesmo que não façamos intercâmbios entre povos distintos, precisamos, em nós mesmos, negociar as múltiplas referências e expressões culturais que possuímos a fim de manifestarmos nossa identidade. Nossa presença no mundo não é, portanto, inocente. Não podemos ou devemos negar quem somos. Para um ator/performer, esta negociação cultural em si mesmo se torna um ato de trabalho constante. Ele precisa, continuamente, revisar o que vai expressar a partir de si, de seu corpo, seu suporte artístico, seja representando, seja apresentando a si mesmo entre as figurações que cria. Neste sentido, um atuador tende a se colocar em constante processo de pesquisa autoetnográfica, investigando as diferentes referências culturais que compõem seu ser a fim de produzir, por meio de sua existência, outras existências. E, por meio delas, dialogar com o mundo.

Étienne Decroux parece ter vivido uma autoetnografia por cerca de seis décadas, o tempo divulgado de seu trabalho na criação/pesquisa e apresentação da arte Mímica Corporal. O que observamos a partir de sua experiência, em especial consigo mesmo, mas também por meio de sua arte nos seus aspectos de transmissão e na relação com a interculturalidade? Podemos compreender que a Mímica Corporal pode ser abordada como uma plataforma artística de incentivo às experiências cênicas, com ênfase corporal, que problematizem a identidade humana que ainda pode ser pretensamente entendida como algo integrado, limitado, fixado. E ela faz isso em procedimentos artísticos bastante rigorosos fisicamente, que lhes são característicos. Seus princípios técnicos não são, porém, para a permanência de uma expressividade de atuação em gestos fixados, mas para a aparição de "ações presentes", como disse o próprio Decroux (1994, p. 144). ${ }^{4}$ Esta arte pode ser também uma base para a criação de expressões específicas em uma atuação, ou seja, pode colaborar diretamente na composição de híbridos performativos corporais nas ações do atuador. Além disso, a Mímica Corporal, ao não desconsiderar o jogo do ator com ele mesmo e com o outro como um elemento importante de trabalho, revela o lúdico a partir do trabalho corporal e sensorial.

Para pluralizarmos esta reflexão, esclarecemos que buscamos também inspiração nos estudos de dois filósofos: Mikhail Bakhtin, sobre arte e responsabilidade e também sobre expressão, e Georges Bataille, sobre a soberania da arte. ${ }^{5}$

Alertamos, porém, para o fato de que na abordagem que aqui fazemos não podemos assegurar que o que dissermos escape de uma utopia de um sonho singular para as artes da cena, com a valorização de um entre-lugar complexo e mistu-
4.

Josef Nadj (1957-...) é um artista que compreende isso bem e propõe concretamente inovações artísticas a partir de suas diversas referências, entre elas a Mímica Corporal Dramática e a Dança contemporânea. Ele diz em uma entrevista:

"Podemos fazer essa analogia e dizer que as criações são a máscara de um coreógrafo. Uma máscara não serve só para esconder, muitas vezes também serve para revelar dimensões escondidas. Tal como as pessoas, também as obras vivem de coisas que nos escapam". (...) "Como pode o gesto falar de algo que está em permanente mudança? Como pode o gesto ser a voz dessa mudança?"

Em: http://www.publico.pt/ culturaipsilon/noticia/ autoretrato-de-um-homem-a-atravessar-um-rio-1661895. Acesso em 02/07/2015.

Conferir também:

http://www.josefnadj.com/.

5.

As proposições de $M$. Bakhtin podem ser conferidas nos livros citados nas referências ao fim deste texto. Sobre o pensamento de G. Bataille, conferir no livro citado na nota 2, em especial p. 131-147. 
rado para a atuação, talvez de difícil concretização continuada por um artista. Não queremos, também, de modo ingênuo e não contextualizado, buscar simplesmente inverter algo considerado como um cânone ou um poder estabelecido, a fim de obtermos o que não possuímos ou abrigar em nós algo que está fora de nossos hábitos com o fim de colecionar repertórios cênicos. E, por outro lado, não pretendemos criar super valores para o que não está no chamado "centro", pois este é uma construção cultural, não uma realidade, como também o é o que está "fora" dele. Queremos, portanto, destacar a noção do encontro como eixo vital para a arte da cena (assim trabalhamos em nossas atividades de pesquisa, criação e ensino). E, com ela, afirmarmos o valor do diálogo, da experiência, da conversação ${ }^{6}$, seja entre o outro e nós ou seja em nós mesmos entre as próprias diferenças de nossa composição cultural humana. Reafirmamos que é importante considerarmos nossa formação por meio de multiplicidades e de mobilidades identitárias culturais. Por isso, desejamos que as possibilidades potentes de uma confluência artística apareçam no convívio entre pessoas e artes, valorizando as diferenças de todas as espécies, tipos, modos, gêneros, etc, buscando, assim, as transcriações possíveis já a partir do trabalho sobre nós mesmos atuadores.

A relação artística que estabelecemos no contato com a arte do mimo corporal toma como princípio de que fazemos parte de uma cultura, no Brasil, permeada pela mistura sincrética, intertextualizada em códigos e referências. Além disso, não desconsideramos algumas experiências que tivemos no campo teatral anteriores a arte de Decroux, no âmbito da formação artística e do trabalho profissional com artistas, propiciando encontros com base na diferença. ${ }^{7}$ Isso nos deu um solo fértil para, ao encontrarmos mais diretamente com a arte francesa Mímica Corporal, compreendermos sua dimensão ética e as possibilidades técnicas artísticas que ela contém para além de atuações formalistas ou de esteticismos. Com ela nos permitimos, então, fazer processos adaptativos para uma atuação contemporânea que se pretenda dialógica. Os modos para isso podem ser mais perceptíveis na prática com esta arte. Mas, aqui buscamos sinalizar alguns caminhos.

Para realizarmos percursos de uma adaptação ou mesmo apropriação de uma técnica artística que é estrangeira a nós, consideramos seus contextos de origem, princípios éticos e treinamentos artísticos específicos em busca de uma artesania $^{8}$ eficaz com ela. Decroux revelava seu receio com um processo artístico intercultural que se realizasse sem aprofundamento anterior na própria experiência de vida do artista ou mesmo com a arte que ele propunha. A noção
6.

Referimo-nos aqui à concepção do "ato de conversar" de Humberto Maturana. Conferir o livro A ontologia da realidade. Belo Horizonte: Ed. UFMG, 1997, p. 167-181, com organização de Cristina Magro, M. Graciano e N. Vaz.

7.

Em 1992 e 1993 participamos como atriz e pesquisadora do grupo "Andarilhos Mágicos" (RJ), criando de modo colaborativo dois espetáculos (palco e rua). o grupo, coordenado pelo Prof. Dr. Rafalele Infante (UFRJ), era formado por pacientes psiquiátricos, estagiários da área de Saúde Mental, além de nós, e assessorados por profissionais desta área. Sua sede era no Teatro Qorpo Santo (RJ), pois o grupo se vinculava ao Instituto de Psiquiatria da UFRJ por meio de oficinas comunitárias do Hospital-Dia e Centro de atenção psicossocial. Em 1993, apresentamos espetáculo do grupo no VII Festival Internacional de Teatro do Oprimido, o primeiro a se realizar no Brasil. Em 2001, ministramos aulas de teatro e dirigimos o espetáculo "Nossa padaria", inspirado em A padaria, de B. Brecht, com a comunidade do Assentamento de Reforma Agrária Dorcelina Folador, em Arapongas-PR, integrante do Movimento dos Trabalhadores Rurais Sem Terra. Este espetáculo integrou a programação do Festival Internacional de Teatro de Londrina (FILO).

8.

A noção de artesania de ator/ performer é uma proposição que fazemos para o trabalho de treinamento e composição artística, relacionados à processos de pesquisa de um atuador. Sua conceitualização é exposta no livro citado na nota 2. 
intercultural trazida por ele poderia estar referenciada e limitada ao intercâmbio entre culturas distintas, ou seja, no convívio entre povos e suas técnicas artísticas diferentes. No contexto da primeira metade do século 20, com a menor experiência de encontro cultural existente, o temor com o trânsito de fronteiras era algo mais evidente. E isso poderia ser compreendido em razão dos riscos de criação de um tipo de sincretismo que resultasse na anulação de dada cultura, em processos de colonização, ou até mesmo em uma manifestação de aspecto exótico fetichista, esvaziando princípios éticos culturais existentes. Decroux não visava uma produção artística "exótica" e demonstrava recear determinado modo de sincretismo. Ele se manteve focado artisticamente em objetivos específicos, ou seja, na criação e defesa de uma arte potente de ator que se comparasse, na sua idealização, com a arte da escultura, da pintura e do desenho. Decroux queria criar uma arte específica de ator. Portanto, conciliar esta motivação com uma prática intercultural, nas percepções acima expostas, poderia ser uma ação inviável para ele. Além disso, Decroux recebia críticas na França por estar criando uma arte que já demonstrava grande diferença para o teatro ortodoxo no ocidente europeu, pois ela não estava assentada em dramaturgias textuais ou mesmo em concepções voltadas para a pesquisa de encenação. Por isso, ao visar outra maneira de jogo para o atuador, ou seja, um jogo que parte da pesquisa do próprio corpo e de sua presença, e com produção de imagens corporais insólitas, podemos compreender que a arte da Mímica Corporal colabora, mas em outra perspectiva, como preparadora para um comportamento intercultural do atuador, ainda que notemos ambiguidades e contradições de seu inventor.

Assim, o princípio intercultural aqui tratado por nós na relação com o mimo corporal é pensado, primeiramente, como o estudo do nível "biológico" do teatro por meio da pesquisa aprofundada do ator/performer sobre si mesmo, uma condição técnica importante na busca da alteridade. Este modo de investigação artística tende, assim, a abrir processos de conscientização no indivíduo artista que explorem sua multiplicidade expressiva. Compreendemos isso como um trabalho de alteridade poética que se inicia no reconhecimento das diferenças que existem em nós mesmos e que nos compõem como ser cultural. Para Decroux, isso é um trabalho que se relaciona à atitude de um artista frente ao mundo. "A atitude é, talvez, mais que uma pontuação de movimento. É talvez o testemunho, o balanço. Em todo caso, é um resultado" (Decroux, 1994, p. 124). E, paralelo a isso, a interculturalidade pode se apresentar como um exercício de fortalecimento de procedimentos téc- 
nicos diferentes de uma atuação ortodoxa ocidental, em bases realistas, com geração de resultados também diferentes.

Para isso, tomamos aqui alguns exemplos de práticas da Mímica Corporal, ancoradas em bases filosóficas-técnicas desta arte, que podem nos auxiliar na discussão sobre procedimentos interculturais com ela: 1. Prática corporal do atuador como pensamento para a pesquisa e a criação: o trabalho de atuação é considerado por Decroux como um ato de desenhar o corpo na relação com o espaço e com o outro. Assim, ele valoriza uma alteração na hierarquia da erudição, valorizando a elaboração do conhecimento por meio do corpo do artista, de sua experiência sensível, e não mediada, primordialmente, pelo estudo livresco, pela leitura. O pensamento se apresenta, portanto, no movimento expressivo corporal e na presença do atuador; 2. Dilatação do ser: treinamento energético e estudo de movimento para um jogo com a tridimensionalidade do corpo; 3. Ocultação do rosto no treinamento do atuador por um véu: o rosto é uma parte do corpo humano considerada por Decroux de limitado trabalho. Ao ocultá-lo, desloca-se um centro expressivo importante do corpo humano no teatro ortodoxo, fazendo aparecer outra "face" no corpo do atuador. Esta pode ser "localizada" no tronco, o que revela outra alteração hierárquica; 4. Criação de ações na relação com a força da gravidade e a alteração de equilíbrio: realização de trabalho com os pés, seja em posicionamentos diferentes, seja por exercícios do repertório mímico corporal sobre "contrapeso" e entre "supressões de suporte"; 5. Intensa interarticulação corporal com bases no jogo da "estatuária móvel" e dos "ritmos dinâmicos"; 6. Jogo com a equivalência: o estudo do outro por meio da criação de equivalentes corporais, ou seja, a revelação de uma transposição, uma suposição do original, uma transcriação. "Encontramo-nos mais ou menos perto da noção de presença que não representa” (Decroux, 1994, p. 150).

A composição de ator embasada na prática do mimo corporal valoriza, assim, descobertas de si em processos, inicialmente, individuais de desconstruções, fragmentações e contrafações corporais. Contrafazer, na arte do mimo corporal, é um ato de jogar com a forma expressiva. Decroux criou, portanto, uma dinâmica de jogo para o atuador que coloca em questão sua identidade cultural humana conhecida antes mesmo de haver um diálogo com o que está além dele. Ele propôs que fosse feita uma pesquisa sobre nós mesmos em um modo de "aculturação" técnica. Com isso, revelou seu desejo de que, ao fim, tudo pudesse se tornar uma presença potente do atuador, podendo este se manter, até, imóvel na sua aparição ou, ainda, sem um tipo de movimento expressivo que revelasse repertórios e padrões téc- 
nicos de sua arte. Neste sentido, sua proposição promove um modo de desestabilização do ser mas, ao mesmo tempo, abre-o ao encontro com um Outro fora dele para uma nova composição. A revelação desta pode se aproximar de uma expressão corporal híbrida, seja no conjunto gestual diferenciado que a própria arte do mimo corporal produz, seja na base técnica que ela dá para outras apropriações e expressões de ator.

Pensamos, assim, que este modo de trabalho de atuação com a Mímica Corporal colabora eficazmente para uma expressividade distinta do atuador que podemos também relacionar com a noção de "monstruosidade", mas sem necessariamente focar-se em objetivos estéticos formalistas. Mas de que "monstro" falamos? Daquele que se fundamenta no jogo com a multiplicidade do movimento expressivo propiciada pelo exercício do mimo corporal e se cria a partir desta experiência abrindo-se a improvisos de atuação com uma produção gestual "misturada".

Esta "mistura" pode se constituir, de modo mais habitual, no excesso expressivo da gestualidade do atuador, no seu ímpeto de ação, na intensidade e grande energia de sua presença. Mas, em continuidade, se mostra também a partir de certa indisciplina e até insolência em relação ao seu trabalho técnico de origem. Mesmo continuando a se alimentar de práticas sobre o corpo desfigurado e contrafeito, esta expressividade problematiza as regras corporais aprendidas no processo de "aculturação técnica". Trata-se, assim, de uma mistura que suscita um devir-outro para além do eu do artista.

O devir-animal está sempre latente em nós; com menos evidência, mas não com menos intensidade, o devir-vegetal e o devir-mineral [e outros que estejam em novas classificações biológicas]. E o que é um devir senão a experimentação de todas as nossas potências _ afetivas, de pensamento, de expressão? (Gil, 2007, p.178) ${ }^{9}$

O híbrido performativo, portanto, pode ser constituído a partir da pesquisa prática da expressividade corporal do artista e da investigação entre seres (eu e outro, sendo corpos de homens e animais; corpos vivos e objetos ou máquinas), gêneros, disciplinas e também de técnicas artísticas. A forma artística híbrida resultante do trabalho de uma atuação performativa, por meio desses conteúdos, tende a gerar um forte estranhamento em quem a recebe, a vê, pois trata-se de algo mostrado que se revela diferente do humano costumeiro, e até de equivalências expressivas, mas que pode despertar uma sensação familiar. Corpos híbridos nas atuações performativas podem, então, nos fazer ver algo que deveria estar escondido no humano ator/performer, mas aparece. A reflexão aqui
9.

O filósofo nos chama também a atenção, por outro lado, para o fato de que não há devir real por meio da monstruosidade, pois os signos desta servem como uma anunciação de algo que sinaliza uma privação, ou seja, a limitação da figuração do corpo teratológico para um devir. O "corpo monstro" sinaliza uma irreversibilidade. Recomendamos a leitura do artigo de José Gil, Metafenomenologia da monstruosidade: o devir-monstro. In: James Donald; Ian Hunter; J. Jerome Cohen e José Gil. Trad. Tomaz Tadeu. Pedagogia dos monstros - Os prazeres o os perigos da confusão de fronteiras. Belo Horizonte: Autêntica, 2007, em especial as páginas 178-180, para o entendimento mais aprofundado de nossa apropriação neste texto sobre as questões da monstruosidade. 
presente sobre o estranho familiar tem base direta no pensamento freudiano sobre o que é inquietante, o estranho.

A palavra "monstro" possui um sentido de revelação de uma conduta a seguir (Gil, 1994, p. 77) e não somente o de mostrar algo. Assim, compreendemos que o caminho da monstruosidade a ser conquistado no processo criativo de uma atuação performativa deve ser atravessado por uma advertência que aponte para uma expressão superabundante e extraordinária do artista, mas que não se reduza à sua forma. "O monstro é sempre um excesso de presença" (Gil, 1994, p. 79). A criatura expressa pelo ator/performer é, portanto, também, uma apresentação da realidade artística corporal, não do realismo naturalismo de uma ação física do artista. Há nesta criatura um transbordamento no material corpóreo que tende a mostrar, aqui sim, o que está submerso nela.

O seu corpo difere do corpo normal na medida em que ele revela o oculto, algo de disforme, de visceral, de 'interior', uma espécie de obscenidade orgânica. O monstro [criatura] exibe-a, desdobra-a, virando a pele do avesso, e desfralda-a sem se preocupar com o olhar do outro; ou para o fascinar, o que significa a mesma coisa (Gil, 1994, p. 83).

Esse caminho de uma atuação intensa, fundada no excesso expressivo, é um dos percursos possíveis para a relação artística com a Mímica Corporal. Nesta perspectiva, existem criações simbólicas de atores/performers cuja expressividade manifestada não necessariamente existe para, somente, se realizar como um ato de reconhecimento de um pensamento nela dos signos originados pela técnica do atuador. Esta expressividade pressupõe algo para além do conhecimento e da comunicação do artista, ou seja, trata-se de uma imagem produzida que, ao se revelar, pede também dialogismos do receptor e se abre, portanto, ao outro que a recebe. Deste modo, a expressão artística do atuador, com bases de investigação criativa na Mímica Corporal, ao se fazer intensa, monstruosa, não visa atrelar-se à categoria da identidade humana para produzir uma expressão. O humano se faz outro, deformando-se do habitual. A gestualidade cultural do cotidiano é explodida e transcriada. Mas, ressaltamos que a imagem artística corpórea do híbrido performativo, ou seja, as ações físicas do atuador neste sentido, é, assim, algo sobre o qual, por fim, não se tem controle sobre como ela será recebida. Ela pode produzir encantamentos por sua experiência viva de busca da metamorfose do ser por meio de ações críveis. Há neste jogo um possível pânico do artista em poder se tornar outro tão diferente de si, ser humano. Mas esta é uma brincadeira de atuar que a Mímica Corporal possibilita, ou seja, uma atuação na fronteira entre a humanidade e a 
possível não humanidade na aparição do híbrido performativo. Para isso, a artesania de ator/performer precisa ser intensa, pois somente assim possibilitará, paradoxalmente, sua dissolução e, consequentemente, o aparecimento da soberania da arte.

Compreendemos que neste século 21 é importante para quem aprende Mímica Corporal poder ser incentivado também a revisá-la buscando, inclusive, transcriar o próprio repertório aprendido. Por outro lado, pode, talvez, haver ainda hoje receio de saída da linguagem que esta arte propõe na direção de maior busca dos híbridos performativos. Este receio poderia ser entendido como um medo do artista em acabar se desvinculando de sua origem formativa, podendo produzir algo que não tenderia a ser "fértil" como arte, ou de difícil continuidade de transmissão. Além disso, o híbrido surgido a partir de uma origem "paterna" artística, poderia ser também considerado um símbolo "herege". Assim, é importante discutir a questão de uma impossibilidade de transmissão da produção artística híbrida, especialmente se ela foi criada a partir de uma pedagogia que se pautou, inicialmente, na aprendizagem de um modelo e na repetição de sistematizações corporais bastante estruturadas. Consideramos que um resultado híbrido não deve ter, por princípio, a motivação de uma reprodução "filial" futura. A transmissão do híbrido performativo pode acontecer na medida em que a expressão intercultural de um atuador faça surgir um tipo de figura, ou exercício técnico, que se torne novo repertório passível de ser repassado a outro artista. Ou seja, o híbrido pode ser "fértil", mas de outra maneira, ou seja, não na perspectiva "familiar" da "filiação paterna (ou materna)" do modelo original. Assim podemos fazer adaptações e transcriações.

Se entendemos que a manifestação híbrida já está presente no próprio repertório mímico corporal, constatamos que ela se mostrou muito potente na sua própria transmissão ao longo de muitas décadas e até hoje. Os resultados de uma atuação híbrida podem, assim, ser transmitidos e gerarem variações expressivas. Essas podem surgir intencionalmente a partir de diretriz dada pelo próprio Decroux em seus princípios de trabalho e procedimentos técnicos. Em peças clássicas do repertório desse artista, como o Carpinteiro, podemos ver que o equivalente mostrado é uma expressão de base mais abstrata artística composta a partir de matrizes de ação realista em atitudes corporais culturais de ofícios profissionais. Este caminho de criação não parou na realização de peças clássicas do artista francês nos anos 30 e 40, mas se tornaram procedimentos de composição instigantes, originando outras peças nas décadas seguintes. Assim, procedimentos como estes para os estudos 
de atuação corpórea, bem como a criação de figuras de estilo, entre outros, são, a nosso ver, caminhos concretamente sinalizados por esta arte para a realização de composições que possam revelar outros híbridos performativos. Por meio de exercícios corporais do repertório decrouxiano, pode-se experimentar possibilidades de criação de outros corpos, outros seres, jogar com a intensidade da presença e a ficção. Sátiros, Medusas, Centauros, Faunos, Cérberos, Minotauros até poderiam ser compostos, jogando com uma atuação que não se caracterizasse, somente, na expressão do fantástico e do alegórico apoiada em máscaras, adereços e figurinos. O corpo pode ser máscara, suposição do original, um equivalente, e Decroux compreendeu bem isso, trabalhando na perspectiva da sistematização de um treinamento para o mascaramento corporal, da recriação do próprio corpo humano, antes mesmo de uma relação do corpo do artista com objetos. Assim, várias figuras originadas da prática com a Mímica Corporal escapam da expressão figurativa representacional. A liberação da figura por um atuador se revela nos traços do jogo de seu corpo com o espaço. Portanto, a representação daqueles seres fantásticos acima citados, e outros, se revelará como apresentação, presentação de um corpo que atua, hibridamente, em uma zona de indiscernibilidade entre o humano e outro ser.

Antonin Artaud possui um comentário importante sobre a atuação de Jean-Louis Barrault, em 1935, que atuava um "Cavalo-centauro". Este ator, à época, havia recentemente realizado um processo de pesquisa prática com Decroux, recebendo ensinamentos da Mímica Corporal, que começava a se fortalecer como uma arte específica. Artaud comenta, assim, que o trabalho de Barrault demonstrava uma ação irresistível do gesto, trazendo magia por meio de uma gestualidade estilizada na expressão de uma figuração fantástica, não humana.

No laboratório cênico decrouxiano, ele próprio parece ter "misturado", especialmente em si e usando sua própria vida, referências da arte da pantomima antiga, que possui gestualidade denominada como "pantomima realista", da dança clássica, da rítmica corporal, da ginástica, da luta, do teatro, inventando um repertório extremamente rico, inusual e inovador para o trabalho de treinamento de um ator. Neste sentido, ainda que de modo aparentemente indireto, o artista pareceu saber que "a força e a saúde de uma cultura medem-se pela sua aptidão a transformar-se; pela sua plasticidade, pela sua apetência em devir, evoluir, provocar grandes mudanças internas" (GIL, 1994, p. 177). Decroux problematizou, portanto, a cultura teatral francesa e nos propicia, com sua arte, buscarmos experiências radicais de composição.

Mas, quem se interessa por compor atuações híbridas hoje, 
de fato? Quem "compra" uma atuação híbrida que problematize sobremaneira atuações realistas naturalistas, ou as dos espetáculos com padrões definidos pelos musicais norte-americanos, rentáveis financeiramente (ainda que mais para os produtores do que para os atores-bailarinos-cantores), ou até mesmo as atuações de expressão épica? A "compra" parece rara e, quando ocorre, talvez não seja, prioritariamente, por razões ideológicas de afirmação sobre a mestiçagem ou sobre o híbrido corpóreo do artista da cena.

Infelizmente, parece também haver ainda preconceitos na recepção de modos de atuação mais voltados aos hibridismos, às contaminações e fusões entre artes. Isso porque o campo das "misturas" em artes é um campo que tende a revelar o disforme, o grotesco, o estranho, o inquieto e, especialmente, o feio. Ora, se assim o é, de fato, parece que estamos, ainda, no tempo atual, realizando algo na contramão histórica, ou seja, uma impertinência, uma subversão artística.

Decroux foi um artista com propostas que subverteram o fazer nas artes da cena e também o pensamento sobre ela. Ele foi muito contestado e também, possivelmente, até hoje, visto somente como um pedagogo corporal que criou uma gramática física para treinar o ator. Este modo de entendimento sobre as proposições que ele fez é muito restrito. Os danos oriundos de não se pensar e praticar a arte decrouxiana para além do seu registro "ginástico" é impedir uma revisão sistematizada de sua pesquisa artística e, assim, bloquear experimentações necessárias para a arte de ator e do teatro (para falarmos de um modo disciplinar).

O fortalecimento de uma experimentação "mestiça" a partir das propostas de Decroux, seja nas Américas, seja no Brasil, pode ser fortalecida também à luz de nossas manifestações culturais espetaculares, de nossas festas e tradições corporais. Para isso, é preciso partir de uma qualidade técnica de execução e experimentação da arte decrouxiana nos repertórios que ela possui, reperformando-as. Fazer isso de modo público, sem fins didáticos ou de pesquisa pode custar caro financeiramente no pagamento de direitos autorais para as obras cênicas de Decroux e seus colaboradores. Mas, com as reperformances, da forma como puderem ser realizadas, abrimos possibilidades de problematizar possíveis ortodoxias artísticas ainda existentes e criar outras expressões simbólicas a partir da arte decrouxiana. Quem conhece o repertório de peças, figuras e movimentos de Decroux, ou mesmo de seus ex-colaboradores diretos, consegue identificar citações expressivas em determinadas atuações cênicas e espetáculos daqueles que fizeram formação em Mímica Corporal. Uma citação, ou 
seja, o uso de fragmentos de determinado repertório pré-existente, é também um modo de "contaminação" artística e um caminho importante para a criação de um existir diferenciado com o que se aprendeu, por anos, com a Mímica Corporal. Pode-se, por exemplo, na criação, manter um núcleo de partitura expressiva física desta arte e fazer surgir outra partitura a partir dela. A ação física híbrida, portanto, origina-se também deste tipo de mistura.

Diante do que já expomos, ressaltamos ainda a luta intensa do artista Decroux em romper paradigmas, digamos, "coloniais" no campo das artes da cena. Se podemos pensar que a arte teatral foi "colonizada" pela literatura dramática e que o ator se subjugou a ela como meio principal para sua composição artística, podemos considerar que Decroux realizou uma ação artística subversiva, anti colonialista, permitindo ao que estava subalterno, falar. Seus processos de pesquisa e criação são, assim, inspiradores, de modo único, para o campo de estudos interculturais nas artes da cena. 


\section{REFERÊNCIAS}

ARTAUD, Antonin. O teatro e seu duplo. Trad. Teixeira Coelho. São Paulo: Martins Fontes, 1999.

BAKHTIN, Mikhail. A Cultura Popular na Idade Média e no Renascimento: o contexto de François Rabelais. Trad. de Yara F. Vieira. São Paulo: Hucitec; Brasília: Editora Universidade de Brasília, 2008.

Estética da criação verbal. Trad. Paulo Bezerra. São Paulo: Martins Fontes, 2003.

BHABHA, Homi K.. O local da cultura. Trad. M. Ávila, E. L Reis e G. Gonçalves. Belo Horizonte: Ed. UFMG, 1998.

BHARUCHA, Rustom. Somebody's other. Disorientations in the cultural politics of our times. In: Patrice Pavis. The intercultural performance reader. Hants: Routledge, 1996.

CANCLINI, N. G. Culturas híbridas. Estratégias para entrar e sair da modernidade. $4^{\text {a }}$ Ed. São Paulo: UNESP, 2011.

DECROUX, Étienne. Paroles sur le mime. $2^{\mathrm{a}}$ Ed. Paris: Ed. Gallimard, 1994.

DELEUZE, G.; GUATTARI, F. Mil platôs. Capitalismo e esquizofrenia. Vol. 5. Trad. P. P. Pélbart e J. Caiafa. São Paulo: Ed. 34, 1997.

DE MARINIS, M.. Il teatro dell'altro. Interculturalismo e transculturalismo nella scena contemporânea. Firenze: La Casa Usher, 2011. FREUD, S.O. O estranho (1919). In: Edição das obras completas de Sigmund Freud. Rio de Janeiro: Imago, 1969. P. 273-320.

GIL, José. Monstros. Trad. José Luis Luna. Lisboa: Quetzal Editores, 1994.

ROLNIK, Sueli. Subjetividade Antropofágica. In: Catálogo da XXIV Bienal de São Paulo: Núcleo Histórico: Antropofagia e História de Canibalismos. Paulo Herkenhoff e Adriano Pedrosa (Edit.). São Paulo: Fundação Bienal de São Paulo, 1998. P. 128-147.

SANTOS, Milton. Por uma outra globalização: do pensamento único à consciência universal. São Paulo: Record, 2000. 